\title{
Dr. Öğr. Üyesi Mehmet Fatih Müderrisoğlu'nun Ardından
}

Murat Kocaaslan $^{1}$ (D)

\section{Eğitimi ve akademik hayatı:}

Dr. Öğr. Üyesi M. Fatih Müderrisoğlu, tapu kadastro memuru Mustafa Kazım ve ev hanımı Yıldız Müderrisoğlu'nun oğlu olarak 06.10.1957 yılında Yozgat'ta dünyaya geldi. ${ }^{1}$ Babasının memuriyeti nedeniyle eğitimini farklı şehirlerde tamamladı. İlköğrenimine Mardin Dumlupınar İlkokulu'nda başladıysa da eğitimini 1963-68 yıllarında Urfa Cengiz Topel İlkokulu'nda tamamladı. Ardından 1968-69 yılında Urfa Merkez Ortaokulu'na ve 1969-70 yılında ise Konya Devrim Ortaokulu'na devam etti. 11.07.1975 y1lında Konya Karatay Lisesi'ni bitirdi.

Müderrisoğlu, 1975 yılında başladığı üniversite eğitiminde öncelikle Hacettepe Üniversitesi İstatistik Bölümü'ne kayıt yaptırdı ancak bir yıl sonra okulu bıraktı. 1979 yılında aynı üniversitenin Arkeoloji ve Sanat Tarihi Bölümü’ne başladı. Bu bölümden 1983 yılında mezun oldu. Mezuniyet tezi olarak “Bursa Yıldırım Bayezid Külliyesi”ni hazırladı. Yüksek lisans ve doktora çalışmalarını Hacettepe Üniversitesi Arkeoloji ve Sanat Tarihi Bölümü’nde Prof. Dr. A. Filiz Yenişehirlioğlu ile yürüten Müderrisoğlu, 1986 yılında “Edirne II. Bayezid Külliyesi” konulu teziyle yüksek lisans, 1993 yilında ise “16. Yüzyıl Osmanlı Imparatorluğu'nda İnşa Edilen Menzil Külliyeler” başlıklı teziyle de doktora eğitimini tamamladı. Müderrisoğlu, doktora tezinde 16 . yüzyılın sosyal, ekonomik ve siyasi yapısıyla, bu olguların mimariye olan uzantılarını mimari ağırlıklı bir yaklaşımla ele aldı. Çalışmasında Saray çevresine mensup sultan, sadrazam, vezirler tarafından Rumeli ve Anadolu yolları üzerinde inşa edilen ve "Menzil Külliyesi” olarak bilinen on dört külliyeyi dönem kaynakları, vakıf kayıtları ışığında detaylı olarak değerlendirmiştir.

Akademik hayatına 1985 yılında Hacettepe Üniversitesi Sosyal Bilimler Enstitüsü’nde başlayan Müderrisoğlu, 1991 yılından itibaren aynı üniversitenin Edebiyat Fakültesi Sanat

1 Bkz. http://www.sanattarihi.hacettepe.edu.tr/cv/fatih_muderrisoglu.shtml (Erişim 10 Haziran 2021); F. Toruk ve F. Bürkük (2020). "Dr. Mehmet Fatih Müderrisoğlu (1957-2020)". Selçuklu Medeniyeti Araştırmaları Dergisi, (5), 172-173; M. Kurtoğlu ve F. Bürkük (2020). "Kendi Dünyasında Bir Seyyah, Sanat Tarihinin İzinde Bir Hoca: Mehmet Fatih Müderrisoğlu”. Vakıflar Dergisi, (54), 289-298. Yazının hazırlanması sırasında yardım ve önerilerinden dolayı; Prof. Dr. Filiz Yenişehirloğlu'na, Prof. Dr. Serpil Bağcı’ya, Prof. Dr. Aykut Misırlıgil’e ve Nevin Aykın'a teşekkür ederim.

'(Doç. Dr.), Hacettepe Üniversitesi, Edebiyat Fakültesi, Sanat Tarihi Bölümü, Ankara, Türkiye. e-mail: muratkocaaslan@hacettepe.edu.tr ORCID: 0000-0002-4306-7112 
Tarihi Bölümü’nde devam etti. 1995 yılında öğretim görevlisi ve ardından 1997 yılından itibaren de öğretim üyesi olarak görevini sürdürdü. Otuz beş yıl süren akademik hayatında; Osmanlı Sanatı, Osmanlı Kentleri, Müzecilik, Erken Osmanlı Sanatı, Osmanlı Döneminde Yazılı ve Görsel Belgeler, Oluşum ve Gelişim Evresinde Osmanlı Sanatı gibi lisans, yüksek lisans ve doktora düzeyinde birçok ders verdi. Ayrıca birçok yüksek lisans ve doktora öğrencisine danışmanlık yaptı.

Müderrisoğlu 1985 yılında Sanat Tarihi bölümüne başlamasının ardından Türkiye ve dünyada birçok yeri gezdi. Yirmi beş yıllık arkadaşı ve aynı zamanda gezilerinde kendisine eşlik eden Prof. Dr. Aykut Mısırlıgil, Müderrisoğlu'nu şöyle anlatmaktadır:

“Fatih Hoca ile yollarımız 1980’li yıllarda kesişti. Uzun yıllar güney doğu illerinde ÖSYM’nin yapmış olduğu sınavlarda görev yaptık. Görev bitiminde kendi imkân ve harcamalarımızla bütün bölgenin kültür varlıklarını gezerdik. Bu süre zarfında onun "ismi ile müsemma" olduğunu fark ettim. Hem evrensel kültür ve sanatı arayan, yeni yerler görme aşk1 ile tutuşan bir "Fatih", hem de soyadı gibi bilgili bir "müderris"di. Peşini bırakmadım. İlkönce Anadolu toprakları kültür varlıklarının envanterini çıkardık. Detaylı bilgisi ile bütün arkeolojik kazı alanlarını bize bir bir gezdirdi, derin ve mukayeseli bilgiler verdi. Ondan sonra Osmanoğullarının ve Roma'nın izinde Kuzey Afrika'ya açılmaya karar verdik. Onun başkanlığını ve planlamasını yaptığı küçük kültür grupları ile Fas Essaura, Volubilis'den başlayarak, Leptis Magna, Sabrata, Camilla, Timgad, Kartaca, Omdurman Sudan sokaklarında bazen Berberiler, Tuaregler ve Bedevilerle beraber olduk, bazen eski Kahire sokaklarında Kıptilerle beraber nargile içtik. Bazen Sultan Baybars'ın mezarında Fatiha okuduk, bazen Akka'da Cezzar Ahmed Paşa'nın mezarında mehter marşı söyledik, bazen de Ürdün Salt'da 10. yıl marşı okuduk. Pirimiz Evliya Çelebi'nin korkusuzluğunu ve atılganlığını örnek aldık. Bazen, otostop, sırt çantalı, at, deve, halk otobüsü, tren ve tekne ile bazen de ucuz bilet yakalayarak business class uçakla gezegeni dolaştık. Bazen 90 kişilik "youth hostel" yatakhanelerde, bazen de çadırda yattık. Tel Brak, Palmyra, Jerash, Krak des Chavaliers, Baalbek, Bekaa Vadisi, Beidettin Sarayı, Petra, Vadi Rum'da, Kerak Kalesi'nde, Selahaddin Kalesi'nde beraberdik. Yine bize İran çöllerinde Yezd, sessizlik kuleleri, Şiraz, Persepolis ve İsfehan'da, Tebriz'de, Hazer denizi kıyılarında, Kutaisi Gürcüstan'da bize liderlik yaptı. Bizim tam bir bağımsız Memlûklü Türk savaşçısı karakterimiz yanında, o zaman zaman yüzü edeple kızaran, hep doğruyu söyleyen, namuslu bir İstanbul beyefendisi idi. Belki de tek kusuru "elindeki malı iyi pazarlayamayan" bir satıcı olması idi. Hayatı Evliya Çelebi gibi geçti, bir gezgin gibi gezegeni dolaştı. Türk Sanat Tarihi, efendi ve bilgili bir akademisyenini kaybetti. Ben de yeri asla doldurulmayacak bir uzun yol arkadaşımı kaybettim". ${ }^{2}$

Prof. Dr. Aykut Mısırlıgil'in de belirttiği üzere Müderrisoğlu yurtiçinde ve yurtdışında sayısız yer gördü. Hem bu süreçten hem de akademik geçmişinden gelen bilgi birikimini insanlarla paylaşma hususunda hep cömert oldu.

2 Sayın Prof. Dr. Aykut Mısırlıgil'e bu yazıyı kaleme aldığı için teşekkür ederim. 


\section{Akademik çalışmaları}

Müderrisoğlu, 1985 yılında başladığı akademik hayatı süresince birçok bilimsel çalı̧̧mada bulundu. Bu çalışmaların bir kısmı kitap veya makale olarak yayımlandı. 1997 yılında Lüleburgaz Belediyesi Kültür Yayınlarından “Lüleburgaz ve Sokullu Mehmet Paşa Külliyesi”, 1995 yılında ise Prof. Dr. Filiz Yenişehirlioğlu, Prof. Dr. Mustafa Akpolat ve Dr. Öğr. Üyesi Suat Alp'le birlikte hazırladıkları “Mersin Evleri” kitabı ise Kültür Bakanlığı tarafından yayımlandı.

Müderrisoğlu, birçok dergide sayısız makale kaleme aldı. Özellikle Osmanlı şehirleri ve Osmanlı külliyeleri üzerine çalışmalar yaptı. Vakıflar Dergisi'nde: “Edirne II. Bayezid Külliyesi”, "Bir Osmanlt-Türk Şehri Olarak Belen”, "Bani Çoban Mustafa Paşa ve Bir Osmanlı Şehri Gebze”, “Osmanlı Maliyesinin Mali Kaynaklart”, "Osmanlı Saray Çevresinin Suriye'deki Vakıf Eserlerinden Bazı Örnekler” ve "Tahir Paşa ve Mudanya'daki Eserleri”; Hacettepe Üniversitesi Türkiyat Araştırmaları Dergisi'nde: “Anadolu'da Önemli Bir Kültürel Merkez: Osmancık”, “Kanunî Sultan Süleyman'ın Baniliğinde Ailesinin Yeri” başlığıyla Osmanlı dini mimarisi ve şehirciliği üzerine önemli makaleler yayımladı. Bununla birlikte Müderrisoğlu, yurtiçinde ve yurtdışına gezip gördüğü yerlerin tanıtımını içeren birçok gezi yazısı da kaleme aldı.

\section{Kurul, yayın üyelikleri ve danışmanlıkları}

Müderrisoğlu, akademik çalışmalarının yanı sıra birçok farklı kurulda görev, farklı dergilerde yayın kurulu üyeliği ve belgesellere danışmanlık yaptı. Görev aldığı kurulur arasında: 19992000 yılları arasında Trabzon ve 2018-2020 yılları arasında Karabük Kültür Varlıkları Koruma Kurulları bulunmaktadır. Farklı tarihler arasında Hacettepe Üniversitesi Türkiyat Araştırmaları Enstitüsü Yönetim Kurulu Üyeliği ve Dergi Hakemliği, Vakıflar Genel Müdürlüğü Vakıflar Dergisi Yayın Kurulu Üyeliği, Türkiye Tabiatını Koruma Derneği Tabiat ve İnsan Dergisi Yayın Kurulu Üyeliğini de sürdürmüştür.

Danışmanlığını yaptı̆̆ belgeseller arasında Nermin Şaman Doğan ile birlikte TRT için 2000-2001 yıllarında “Külliyeler”, 2008-2009 y1llarında ise “Konuşan Tarih" bulunmaktadır. Bununla birlikte Avrasya televizyonunda yayınlanan "Şehirler ve Camiler" belgeselinin “Ankara Camileri” bölümünde de danışmanlık yapmıştır.

Dr. Öğr. Üyesi M. Fatih Müderrisoğlu, 63 yıllık hayatını bilime katkı yapmak, yeni yerler keşfetmek ile geçirdi. Çalışkan ve beyefendi kişiliğiyle bilinen Müderrisoğlu ne yazık ki 27 Ekim 2020 yılında kalp yetmezliği sonucu hayatını kaybetti.

\section{Bibliyografya}

\section{Kitap ve kitap bölümleri}

Müderrisoğlu, M. F. (1995). Mersin Evleri. Ankara: Kültür Bakanlığı Yayınları. (Filiz Yenişehirlioğlu, Mustafa Akpolat ve Suat Alp ile birlikte)

(1995). “Antalya Mozaik Dünyasında Bir Gezinti”, In Memorian İ. Metin Akyurt-Bahattin Devam Anı Kitabı. (Ed. Nezih Başgelen). İstanbul: Arkeoloji ve Sanat Yazıları, 223-226. 
(1997). Lüleburgaz ve Sokullu Mehmet Paşa Külliyesi. İstanbul: Lüleburgaz Belediyesi Kültür Yayınlar1.

(2001). “Osmanlı Şehirciliği Üzerine Bazı Gözlemler”. Prof. Dr. Zafer Bayburtluoğlu Armağanı Sanat Yazıları. (Ed. M. Denktaş ve Y. Özbek) Kayseri: Kayseri Büyükşehir Belediyesi Kültür Yayınları, 387-396.

(2002). “Osmanlı İmparatorluğu'nda Ulaşım ve Yol Şebekesi”. Ortaçağ’ da Anadolu, Prof. Dr. Aynur Durukan’a Armağan. (Ed. N. Şaman Doğan) Ankara: Hacettepe Üniversitesi Yayınları, 373-381.

(2010). “Kuşevleri”. Şefkat Estetiği Kuşevleri. İstanbul: Zeytinburnu Belediyesi Yayınları, 147-169.

(2011). “Osmanlı Klasik Dönem Yapısı: Konya’da Selimiye Camii”, Anadolu Kültürlerinde Süreklilik ve Değişim, Dr. A. Mine Kadiroğlu’na Armağan. (Ed. B. İşler, E. Ceren, G. Sağır ve N. Peker). Ankara: Hacettepe Üniversitesi Yayınları, 431-440.

(2013). "Demirci İlçesi”. Türk Kültür Varlıkları Envanteri, 45. Manisa İlçeleri. (Ed. H. Acun). Ankara: Türk Tarih Kurumu Yayınları, 1-52.

(2013). “Osmanlı Devleti’nde Vakıf Medeniyeti: Bani ve Şehir İlişkisi”. Vakıf Medeniyeti ve Şehir. Ankara: Vakıflar Genel Müdürlüğü Yayınları, 51-66.

(2014). "Sultan II. Selim'in Banilik Faaliyetleri”. Sanat Tarihi Araştırmaları: Kültürel Kimlikte Gelenek, Çeşitlilik ve Değişim, Prof. Dr. H. Acun Armağanı. Turkish Studies. C.9/S.10: 749-773.

(2018). “Osmanlı'da Bir Saraylı Kadın: Bülbül Hatun ve Amasya'daki Vakıf Eserleri”. Vakıf ve Toplum Vakıf Kuran Kadınlar. (Ed. Abdülkadir Dündar), Ankara: Vakıflar Genel Müdürlüğü Yayınları. 62-69.

(2018). “Ahi Yerleşimi Mudurnu ve Yıldırım Külliyesi”. 2018 Uluslararası Mudurnu Araştırmaları Ahilik ve Halk Kültürü Sempozyumu.(Ed. A. Aktaş Yasa ve F. Öztürk). 21-22 Eylül 2018: 237-254.

(2019). "Klasik Dönem Osmanlı Mimarisi”. Türk İslam Sanatları Tarihi. (Ed. Abdülkadir Dündar). Ankara: Grafiker Yayınları, 339-46.

(2019). “Osmanlı Batılılaşma Dönemi Mimarisi”. Türk İslam Sanatları Tarihi. (Ed. Abdülkadir Dündar). Ankara: Grafiker Yayınları, 347-353.

\section{Ansiklopedi maddeleri}

(1999). “Osmanlı İmparatorluğu’nda Menzil Yolları ve Menzil Külliyeleri”. Osmanlı. C.10. Ankara: Yeni Türkiye Yayınları, 376-383.

(2000). "Menzil Roads and Menzil Complexes in The Ottoman Empire". The Great Ottoman Turkish Civilization. V.4. Ankara: Yeni Türkiye, 380-88.

(2001). “Menzil Kavramı ve Osmanlı Devleti’nde Menzil Yerleşimleri”. Türkler Ansiklopedisi. C. 10. Ankara: Yeni Türkiye Yayınları, 920-926.

(2009). “Havsa Sokullu Mehmed Paşa Külliyesi”. Türkiye Diyanet Vakfı İslam Ansiklopedisi. C. $37: 359-360$.

(2009). "Lüleburgaz Sokullu Mehmed Paşa Külliyesi”. Türkiye Diyanet Vakfı İslam Ansiklopedisi. C.37: 363-364.

(2009). "Payas Sokullu Mehmed Paşa Külliyesi”. Türkiye Diyanet Vakfı İslam Ansiklopedisi. C.37: $364-366$. 


\section{Makaleleri}

(1991). “Edirne II. Bayezid Külliyesi”. Vakıflar Dergisi. S.22: 151-198.

(1994). "Bir Osmanl1-Türk Şehri Olarak Belen". Vakıflar Dergisi. S.24: 237-272.

(1995). "Bani Çoban Mustafa Paşa ve Bir Osmanlı Şehri Gebze”. Vakıflar Dergisi. S.25: 67-124.

(1998). “Osmanlı Maliyesinin Mali Kaynakları”. Vakıflar Dergisi. S.27: 95-101. (Çetin Arslan ile birlikte).

(2003). “Mihaloğulları ve Gazi Mihal'in Bilecik-Gölpazarı'ndaki Eserleri”. Süleyman Demirel Üniversitesi Fen ve Edebiyat Fakültesi Sosyal Bilimler Dergisi. S.8: 207-238. (Çetin Arsalan ile birlikte).

(2006). “Osmanlı Saray Çevresinin Suriye'deki Vakıf Eserlerinden Bazı Örnekler". Vakıflar Dergisi. S.29: 163-190.

(2008). “Anadolu’da Önemli Bir Kültürel Merkez: Osmancık”. Hacettepe Üniversitesi Türkiyat Araştırmaları Dergisi. S.9: 425-438.

(2013). "Vakıflar Dergilerinin İlk Sayılarının Sayısal ve Tematik Olarak Değerlendirilmesi". Vakıflar Dergisi 75. Yıl Özel Sayısı: 75-85.

(2013). “Kanunî Sultan Süleyman'ın Baniliğinde Ailesinin Yeri”. Hacettepe Üniversitesi Türkiyat Araştırmaları Dergisi. S.18 (18): 187-205.

(2018). “Tahir Paşa ve Mudanya'daki Eserleri”. Vakıflar Dergisi. S.50: 199-217.

(2019). "Bir Çınarın Ardından: Prof. Dr. Hakkı Acun' un Yaşam Öyküsü ve Bilimsel Kişiliğì”. 80. Vakıflar Dergisi 80.Yıl Özel Sayısı: 289-294. (Bülent İşler ile birlikte).

S.3: 64-66.

(1989). "Lüleburgaz Sokullu Mehmed Paşa Külliyesi”. Türkiye İş Bankası Kültür ve Sanat.

(1990). “Mimar Sinan'ın Ana Yollar Üzerine İnşa Ettiği Menzil Külliyeleri”, Kültür Bakanlığı Milli Kültür Dergisi. S.71: 27-29.

(1990). “Edirne II. Beyazid Külliyesi”. Türkiye İş Bankası Kültür ve Sanat. S.5: 63-68.

(1990). “Osmanlı İmparatorluğu’nun Doğu Akdeniz'deki İskelesi: Payas ve Sokullu Mehmed Paşa Külliyesi”. Türkiye İş Bankası Kültür Sanat. S.8: 61-63.

(1991). “Afşin Eshab-1 Keyf Külliyesi Hanı”. Türkiye İş Bankası Kültür ve Sanat Kahramanmaraş Özel Sayısı. S.10: 12-15.

(1991). “Terkedilen Yerleşme Yeri Karaköy’de Bir Gezinti”. PTT Dergisi, S.100: 28-31.

(1991). "Safranbolu”. Image of Turkey, S.41.

(1994). “Tokat Hatuniye Külliyesi”. Türkiye İş Bankası Kültür ve Sanat Tokat Özel Sayısı. S.24: $26-29$.

(1994). “Bani Pertev Mehmed Paşa ve İzmit’teki Vakıf Eserleri”. Tarih Çevresi. S.13: 39-46. (1995). "Tarihte Yaşayan Bir Osmanlı Kenti: Safranbolu”. Tarih Çevresi. S.16: 43-48.

(1995). "XV. Yüzyılda Osmanlı İmparatorluğu'nun Bir Hastanesinde Çağını Aşan Uygulamalar".

Sandoz. S.3: 10-19.

(1998). "Tarihsel Süreç İçerisinde İznik”. Vakıf ve Kültür. S.1/3. (Kasım): 43-46.

(1999). "Çandarlı Ailesinin Osmanlı Mimarisi ve Şehirciliğine Olan Katkısı”. Vakıf ve Kültür. S.1/4. (Illkbahar): 55-58 (Çetin Arslan ile birlikte). 
birlikte).

(1999). "Dünden Bugüne Halfeti”. Vakıf ve Kültür. S. 2/6: (Aralık): 16-19 (Çetin Arslan ile

(2002). "Bir Başkent’in Öyküsü: Ankara”. Vakıf ve Kültür: II/Özel Sayı. (Nisan): 82-86.

(2000). "Osmanlının 700. Y1l Anısına". Bilge. S.26: 118-120.

(2010). “Orhan Cezmi Tuncer, Anadolu Kervan Yolları”. Anadolu ve Çevresinde Ortaçağ.

S.3: $217-220$.

(2010). "Dünya Kültür Miras Listesinde Bir Anadolu Kenti: Safranbolu”. İmaret. S.2: 40-44.

\section{Yayın tanitımı}

(2016). “Kurtoğlu Mehmet. Taceddin Dergâhı'nda İstiklal Şairi Mehmet Akif” Vakıflar Dergisi. S.46: 201-203.

\section{Gezi-Seyahat Yazıları}

(1990). "Sinan's Work in İzmit”. TÜTAV Image of Turkey. S.35: 31-32.

(1991). "Beatiful Dalyan". TÜTAV Image of Turkey. S.37: 16-19.

(1992). "The Scener of Great Battles: Issus and Today's Erzin”. TÜTAV Image of Turkey.

S.48: $18-22$.

(1993). "A Tour of Fethiye and Surrounding”. TÜTAV Image of Turkey. S.60: 22-28.

(1993). "Bir Sayfiye Yöremiz Arsuz”. Shell İlgi. S.74: 16-23.

(1993). "Dalyan". Turkish Airlines Skylife. S.123. (Temmuz): 38-47.

(1993). "Kaş’ta Bir Mola”. Kültür. 99: 24-28.

(1993). “The Triangular Paradise Üçağız-Kekova-Simena”. TÜTAV Image of Turkey. 58: 26-29.

(1995). "From Fethiye to Demre: A Travel Diary". Shell İlgi. S. 82: 16-25.

(1998). “Sevginin Buluşamadığı Belde, Daphne”. Tabiat ve İnsan. S.3: 21-23.

(1999). "Doğanın Ve Tarihin Kucaklaştığı Bir Yöremiz; Erzin”. Tabiat ve İnsan. S.2: 27-28.

(2005). “Akçakoca (Diapolis)”. Tabiat ve İnsan. S.3: 39.

(2005). "Kastamonu: An open air museum”. Diplomat. (October): 44-45.

(2006). "Manisa: A break in the Aegean". Diplomat. (May): 39-41.

(2006). "Tokat: Living with tradition”. Diplomat. (June). 46-47.

(2006). "Morocco: Citabel of Suprise". Diplomat. (April): 32-35 (Ünal Araç ile birlikte).

(2006). “Amasya: The Flow of history”. Diplomat. (January): 46-47.

(2015). “Amasya: Kral ve Şehzade Kentinden Müzeler ve Masal Kentine Bir Seyahat Güncesi”.

İmaret. S.17: 108-112.

\section{Kaynakça/References}

http://www.sanattarihi.hacettepe.edu.tr/cv/fatih_muderrisoglu.shtml (Erişim 10 Haziran 2021)

Kurtoğlu M. ve F. Bürkük (2020). "Kendi Dünyasında Bir Seyyah, Sanat Tarihinin İzinde Bir Hoca: Mehmet

Fatih Müderrisoğlu”. Vakıflar Dergisi, (54), 289-298.

Toruk F. ve F. Bürkük (2020). “Dr. Mehmet Fatih Müderrisoğlu (1957-2020)”. Selçuklu Medeniyeti Araştırmaları

Dergisi, (5), 172-173. 


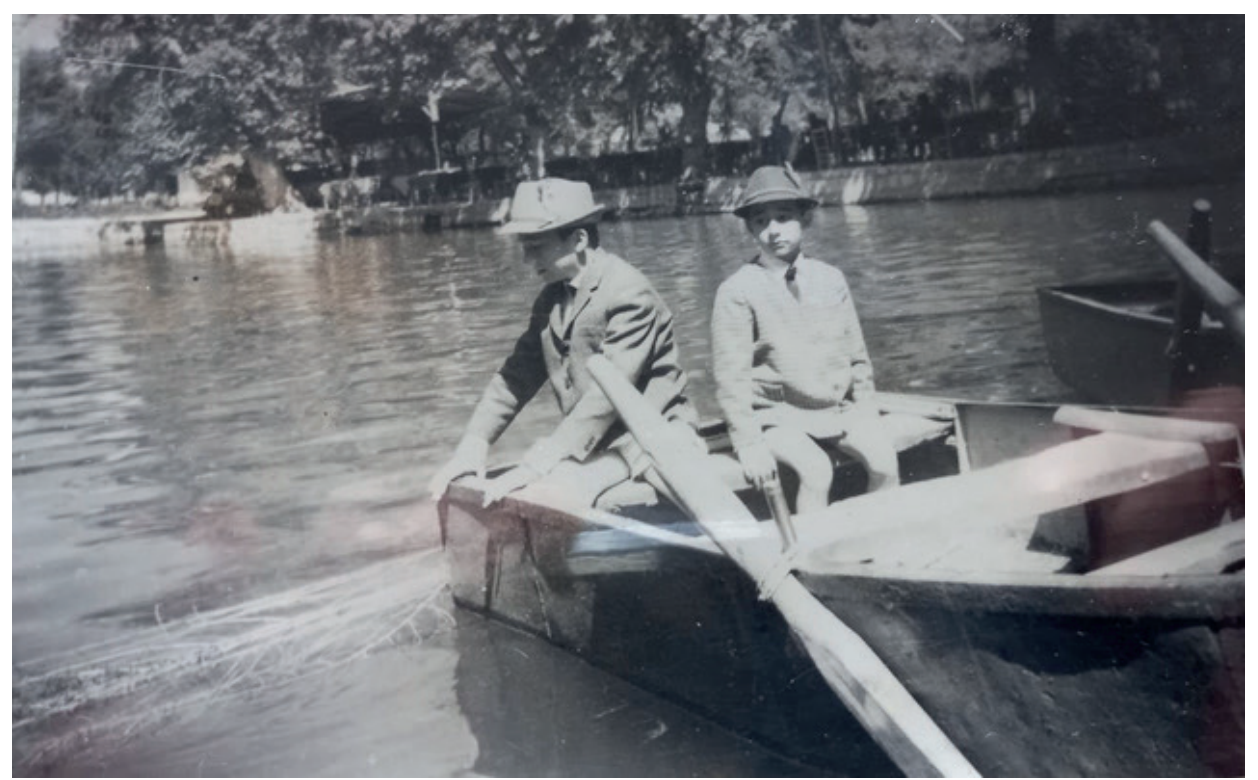

Resim 1: Fatih ve Mustafa (Kardeşi) Müderrisoğlu 1971 yılı (Nevin Aykın Arşivi)

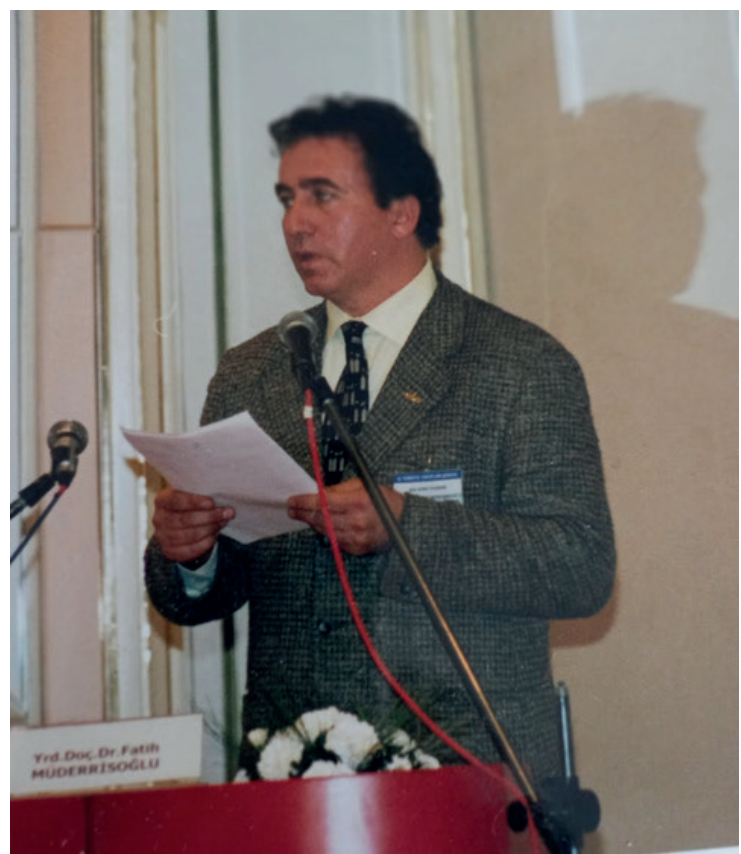

Resim 2: Fatih Müderrisoğlu 1997 yılında sempozyum sırasında sunum yaparken (Nevin Aykın Arşivi) 


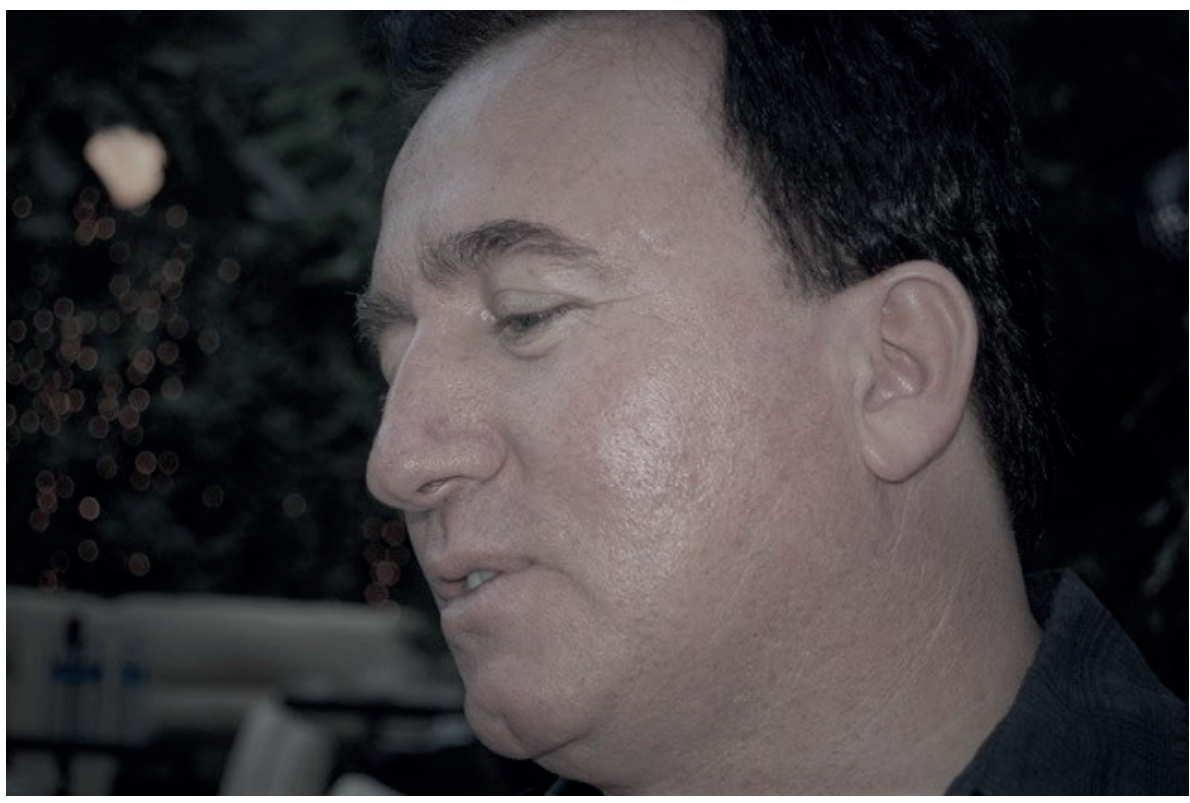

Resim 3: Fatih Müderrisoğlu 2007 yıll, Ankara

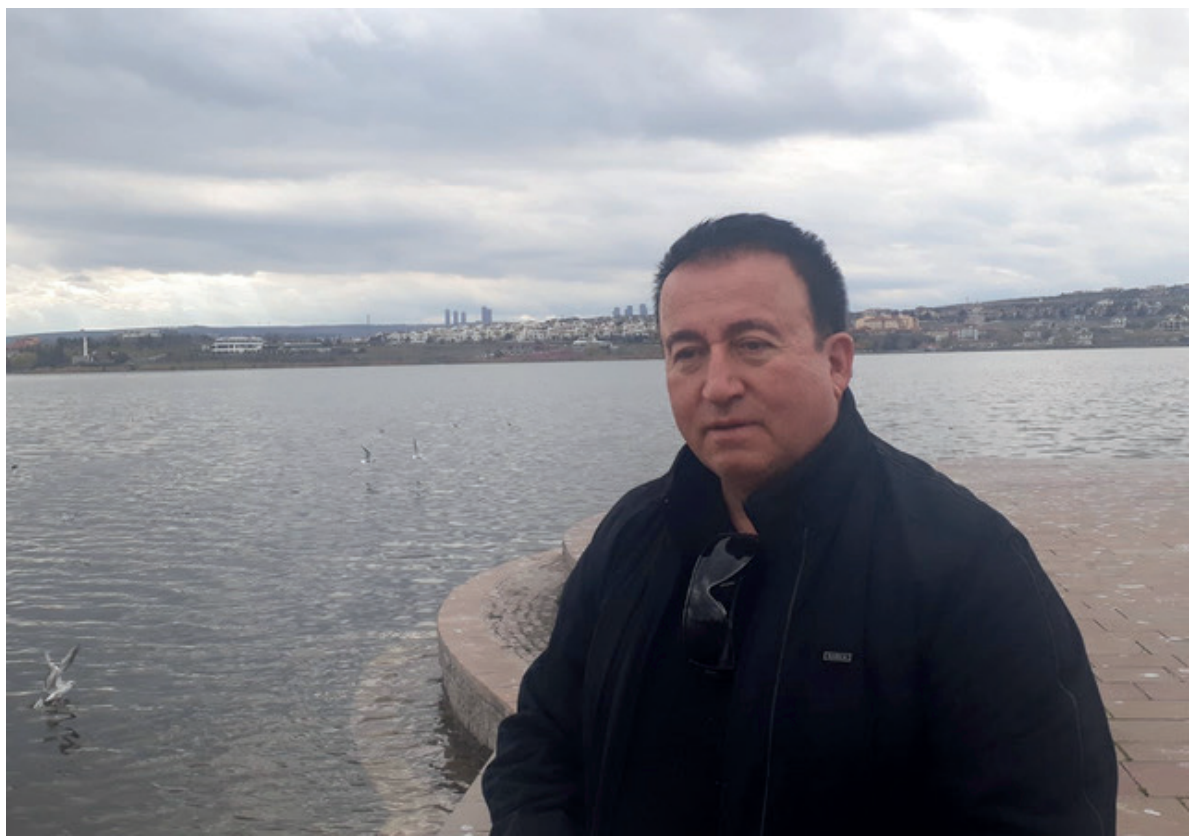

Resim 4: Fatih Müderrisoğlu 2019 yılı Ankara, Gölbaşı (Nevin Aykın Arşivi) 